\title{
Pharmacovigilance of conventional therapy in 250 cases of vitiligo at tertiary specialty care
}

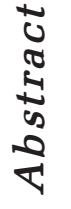

Ashok Kumar Gupta, Shyam Sunder Pandey ${ }^{1}$, Bajrang Prasad Lal Pandey

Departments of Pharmacology, ${ }^{1}$ Dermatology and Venereology, Institute of Medical Sciences, Banaras Hindu University, Varanasi, India

Address for the Correspondence: Prof. B. L. Pandey, Department of Pharmacology, Institute of Medical Sciences, Banaras Hindu University, Varanasi - 221 005, India. E-mail: blp53@rediffmail.com

\begin{tabular}{|l|}
\hline Access this article online \\
\hline Website: www.ijmedph.org \\
\hline DOI: 10.4103/2230-8598.109326 \\
\hline Quick response code: \\
\hline
\end{tabular}

\begin{abstract}
Aims and Objectives: Adverse drug reaction (ADR) may infringe upon compliance, which compromises therapy outcomes in chronic diseases. Our study focused on pharmacovigilance in stigmatizing disease vitiligo, concern with improving disease management incorporating current medical knowledge. Materials and Methods: Therapies in 250 vitiligo cases were scrutinized over period of six months, examining consistency to consensus approach and profiling of the adverse effects. Results: Adverse drug effects occurred in fifth of localized and third of generalized vitiligo patients. Adherence to consensus line of therapy resulted significantly in less adverse effect incidence, and steroid overtreatment was major determinant of risk. Conclusion: Consistency of treatment to consensus approach based on disease extent is prudent to reduce adverse drug effects in vitiligo. Increased vigilance, due psycho-social address, and incorporation of safe and efficacious new immunomodulator drugs is emphasized for consideration toward improved current vitiligo management.
\end{abstract}

Key words: Adverse drug reactions, guideline, pharmacovigilance, vitiligo

\section{INTRODUCTION}

Vitiligo, the stigmatizing skin disease, has prevalence ranging from $0.5 \%$ in the east to $4 \%$ in extreme west regions in India. ${ }^{[1,2]}$ Modern therapeutic options include topical immunomodulators, photochemotherapy, excimer laser, and surgery. No single therapy is regarded as the most effective since success varies with type and location vitiligo. Objective of present treatments is to regain pigment in vitiligenous areas rather than controlling the disease process. Treatment is essentially long-term, hence issue of safety remains important consideration. Corticosteroids, both topical and systemic, have been used in vitiligo for over half a century. There is continuing concerns of steroidal efficacy as well as the adverse effects. Corticosteroids and photochemotherapy using combination of psoralein and sun radiation or UV-A exposure are the most widely prescribed conventional therapies for vitiligo. Newer immunomodulators, protective antioxidants, nutrient supplement etc., are proposed as useful in vitiligo treatment. Preferences for time-honored conventional economical therapy has hindered due exploration of new therapeutic options in vitiligo. Nevertheless, adverse effects of steroids and photochemotherapy remain persistent concerns. The efficacy versus adverse effect issues call for focused re-assessment to utilization of alternative rational therapy options. Present study in 250 vitiligo patients explores adverse effect profile of conventional therapy. Scope for alternative options toward better outcomes may be also appraised.

\section{MATERIALS AND METHODS}

Two hundred and fifty cases seeking medical help purely for vitiligo and no other complaints were included in the study. Some of these cases were discovered with defective thyroid function and were referred for appropriate endocrinological care but not excluded from study. Diagnosis and therapeutic prescription were at discretion of the clinical specialist. Patients were explained of the study and were assured of keeping their identity secret. Free informed consent was thus obtained for their participation. Detailed personal and disease history was elicited, and prescribed therapies were recorded. Total lesion area as percent of body surface was assessed in order to gauze the prescribed therapy as consistent or otherwise to consensus therapeutic guidelines. ${ }^{[3,4]}$ This is explicit as described in Table 1.

Patients reporting fresh or those already under management were included. They were followed 
over six month period involving monthly visit for review. At each visit, questions were asked to ascertain uninterrupted treatment and any troubling adverse effects proactively. Examination to detect cutaneous adverse effect was next performed. Patients were segregated by the prescribed treatment regimens and conformity of the same to consensus guidelines. Predictable and other adverse effects with the regimens were recorded. Rates of adverse reactions noted to occur in patients stratified by age, sex, duration, and concurrent thyroid disorder were compared and analyzed using Fisher's exact statistic.

\section{RESULTS}

The incidence of adverse effects attributable to treatment exhibited increase with increasing disease extent and intensity of therapy from one fifth in localized to one third in extensive vitiligo patients [Table 2].

Psoralein photochemotherapy employed in spread out lesions was particularly associated with ocular photosensitivity as well as systemic maliaze of headache, nausea, and vomiting. Skin burns resulted also in one tenth of cases. Milder consequences like inflammation, pruritus, and hyperpigmentation occurred nearly to same frequency [Table 3].

Steroid monotherapy in regimen 1 also had skin complaints as major adverse consequence including pruritus and skin inflammation as well as atrophy. Incidence of skin atrophy increased in sequential regimens in combination with photochemotherapy. Steroid did associate also with systemic complaints of headache, nausea, and skin hyperpigmentation in some patients [Table 3].

Extent-wise prescription of therapy as per consensus rules very significantly prevented the incidence of adverse effects overall. Adverse effects also occurred significantly less frequently in younger patients. There was no significant difference in rate of adverse effects among sexes or in regard to early or late stages of disease. Though thyroid dysfunction was found only in $12 \%$ of cases, there was significant reduction in adverse effects associated with vitiligo treatment [Table 4].

\section{DISCUSSION}

Adverse effects play important role in poor compliance to therapy. Reported high non-compliance rates in vitiligo may be due to such adverse effects. ${ }^{[5]}$ Ocular problems, headache, nausea, and vomiting are recognized adverse effects of oral steroids and PUVASol therapy. ${ }^{[6,7]}$ These occurred most frequently in regimen 3 , whereas the frequencies are less in regimen 2. Skin atrophy was more frequent in regimen 3 followed by regimen 2, and may be due to added strong topical corticosteroid. Steroids cause biochemical changes in skin lipids, disturbing water homeostasis. ${ }^{[8]}$ The least adverse reactions in regimen 1 may be due to use of mild potency topical corticosteroid. Frequent hyperpigmentation in regimen 3 followed by regimen 2 may be due to exaggerated reaction to sun light. Drug in vitiligo patients are singularly the major determinants of adverse effects risk.

Prescribed treatment was examined for conformity with the referred guidelines stated in method section. ${ }^{[3,4]}$ Digression of guideline for

\begin{tabular}{|c|c|c|c|}
\hline Regimen & $\begin{array}{l}\text { Number } \\
\text { of cases }\end{array}$ & $\begin{array}{l}\text { Drug used (alone or in } \\
\text { combination) }\end{array}$ & $\begin{array}{l}\text { Consensus } \\
\text { or guideline }\end{array}$ \\
\hline Regimen 1 & 60 & $\begin{array}{l}\text { Topical fluticasone propionate } \\
0.05 \%\end{array}$ & $\begin{array}{l}\text { Adequate } \\
\text { for under } \\
3 \% \text { BSA } \\
\text { affliction }\end{array}$ \\
\hline Regimen 2 & 99 & $\begin{array}{l}\text { Topical fluticasone propionate } \\
0.05 \% \text { clobetasol propionate } \\
0.05 \% \text { in combination } \\
\text { with oral methoxsalene } \\
(0.6 \mathrm{mg} / \mathrm{kg} \text {, E.O.D.) with sun } \\
\text { light exposure }\end{array}$ & $\begin{array}{l}\text { For lesions } \\
\text { exceeding } \\
3 \% \text { and up } \\
\text { to }<10 \% \\
\text { BSA but not } \\
\text { aggressively } \\
\text { progressive }\end{array}$ \\
\hline Regimen 3 & 91 & $\begin{array}{l}\text { Oral methoxsalene } \\
(0.6 \mathrm{mg} / \mathrm{kg}, \text { E.O.D.) with } \\
\text { sun light exposure+topical } \\
\text { clobetasol propionate } 0.05 \% \\
\text { with or without topical } \\
\text { mometasone furoate } 0.01 \%+ \\
\text { oral prednisolone }(0.5 \mathrm{mg} / \mathrm{kg} \text { as } \\
\text { pulse therapy)+ antacids and } \\
\text { antioxidant } 1 \text { capsule per day } \\
\text { (containing lycopene } 3 \mathrm{mg})\end{array}$ & $\begin{array}{l}\text { Progressive } \\
\text { lesions } \\
\text { afflicting } \\
\text { more than } \\
3 \% \text { BSA or } \\
\text { any lesion } \\
\text { exceeding } \\
10 \% \text { BSA }\end{array}$ \\
\hline
\end{tabular}

\begin{tabular}{lccc} 
Table 2: Occurrence rate of any adverse effects \\
under different treatment regimens \\
\hline Regimens & $\begin{array}{c}\text { Total number } \\
\text { of patients }\end{array}$ & $\begin{array}{c}\text { Patients affected } \\
\text { with any ADR }\end{array}$ & $\begin{array}{c}\text { Percent } \\
\text { incidence }\end{array}$ \\
\hline Regimen 1 & 60 & 12 & 20 \\
Regimen 2 & 99 & 26 & 26.26 \\
Regimen 3 & 91 & 30 & 32.96 \\
\hline
\end{tabular}

$\mathrm{ADR}=$ Adverse drug reaction

\begin{tabular}{|c|c|c|c|c|}
\hline \multirow[t]{2}{*}{ Adverse effects } & \multicolumn{4}{|c|}{ Drug regimens } \\
\hline & $\underset{n=60}{\operatorname{Regimen} 1}$ & $\begin{array}{c}\text { Regimen } 2 \\
n=99\end{array}$ & $\underset{n=91}{\operatorname{Regimen} 3}$ & $\begin{array}{c}\text { All } \\
\text { combined } \\
n=250\end{array}$ \\
\hline Hyperpigmentation & 3.33 & 8.08 & 12.09 & 8.4 \\
\hline Pruritus & 8.33 & 9.09 & 6.59 & 8 \\
\hline $\begin{array}{l}\text { Sun sensitivity } \\
\text { and sun burn }\end{array}$ & 5 & 10.10 & 13.19 & 10 \\
\hline $\begin{array}{l}\text { Skin eruptions } \\
\text { and inflammation }\end{array}$ & 1.67 & 7.07 & 8.79 & 6.4 \\
\hline Skin atrophy & 5 & 11.11 & 12.09 & 10 \\
\hline Ocular irritation & 1.67 & 20.20 & 26.37 & 17.2 \\
\hline $\begin{array}{l}\text { Headache, } \\
\text { nausea, and } \\
\text { vomiting }\end{array}$ & 5 & 18.18 & 20.88 & 16 \\
\hline
\end{tabular}

regimen 1 represents overtreatment while that for regimen 2 and regimen 3 drugs is undertreatment. Greater depigmentation area increases anxiety in patient, and overtreatment decision by clinical may be compelled. Such decisions significantly caused increase in risk of adverse effects. The evidence is prohibitive to digression from standard therapeutic guideline based on disease extent. Patients under 16 years significantly suffer less adverse effects, this aspect requires in-depth exploration. 


\begin{tabular}{|c|c|c|c|}
\hline $\begin{array}{l}\text { Probable } \\
\text { determinants }\end{array}$ & $n$ & $\begin{array}{l}\% \text { incidence of } \\
\text { adverse effects }\end{array}$ & $\begin{array}{c}\text { Fisher's exact } \\
\text { test } P \text { value }\end{array}$ \\
\hline \multicolumn{4}{|l|}{ Treatment decision } \\
\hline As per guidelines & 167 & 12.57 & $<0.0001$ \\
\hline Not as per guidelines & 83 & 56.63 & \\
\hline \multicolumn{4}{|l|}{ Age } \\
\hline Up to 16 years & 80 & 17.5 & $<0.0121$ \\
\hline$>16$ years & 170 & 31.76 & \\
\hline \multicolumn{4}{|l|}{ Sex } \\
\hline Males & 112 & 22.32 & NS \\
\hline Females & 138 & 31.16 & \\
\hline \multicolumn{4}{|l|}{ Disease duration } \\
\hline Up to 5 years & 129 & 25.58 & NS \\
\hline$>5$ years & 121 & 28.93 & \\
\hline \multicolumn{4}{|l|}{ Thyroid disorder } \\
\hline Present & 30 & 20.91 & $<0.0001$ \\
\hline Not present & 220 & 73.33 & \\
\hline
\end{tabular}

Few patients who reported thyroid disorder had significantly less rate of adverse effects. But, such cases were few, and acquired parallel care of endocrinologists.

Vitiligo is a chronic disease provoking concerns over major adverse effect of drugs. Immunopathologic understanding has led to new options, tacrolimus and pimecrolimus. ${ }^{[0]}$ These agents were not prescribed despite reported impressive success in vitiligo therapy. Local large scale studies with these therapies in diverse people may be necessary to convince traditional dermatologists. Short course of such drugs in combination with conventional therapies and evaluation of benefit/risk ratios may be reasonable way of their incorporation in routine management.

Possibly adverse effects may be less if innocuous adjunct therapies, such as pseudocatalase and ginkgo biloba extract, are included where feasible. Placental extract melagenina may also seem safe as adjunct and deserves evaluation.
In the present scenario, there is preference solely for conventional agents. Similar was noted in respect of psoriasis therapy (Gupta et al. 2012). ${ }^{[10]}$ Observations of the study suggest need for vigilance and regular monitoring of conventional treatment to detect unwanted effects and risks. Uncertainties of therapeutic response may be reduced by addressing social and psychological stress and by minimizing adverse effects. Consequent improvement of therapeutic compliance would definitively add to quality clinical management of vitiligo.

\section{REFERENCES}

1. Kent G, Al'Abadie M. Psychologic effects of vitiligo: A critical incident analysis. J Am Acad Dermatol 1996;35:895-8.

2. Ongenae K, Beelaert L, Van GN, Naeyaert JM. Psychosocial effects of vitiligo. J Eur Acad Dermatol Venereol 2006;20:1-8.

3. TaïebA, Picardo M. Clinical practice. Vitiligo. N Engl J Med 2009;360:160-9.

4. Gawkrodger DJ, Ormerod AD, Shaw L, Mauri-Sole I, Whitton ME, Watts MJ, et al. Therapy Guidelines and Audit Subcommittee, British Association of Dermatologists; Clinical standards department, Royal college of physicians of London; Cochrane Skin Group; Vitiligo Society. Guideline for the diagnosis and management of vitiligo. Br J Dermatol 2008;159:1051-76.

5. Al-Aboosi MM, Ajam ZA. Oral photochemotherapy in vitiligo: Follow-up, patient compliance. Int J Dermatol 1995;34:206-8.

6. Tegner E. Oral 8-methoxypsoralen photochemotherapy of psoriasis. Acta Derm Venereol 1983;107:107 10.

7. Bourkes RJ, Balen ATM, Bruynzeel DP. A retrospective study of ocular findings in patients treated with PUVA. Dot Opthalmol 1985;59:11-9.

8. Patel T, Bhutani T, Busse KL, Koo J. Evaluating the efficacy and safety of calcipotriene/betamethasone ointment occluded with a hydrogel patch: A 6-week bilaterally controlled, investigator-blinded trial. Cutis 2011;88:149-54

9. Hossani-Madani AR, Halder RM. Topical treatment and combination approaches for vitiligo: New insights, new developments. G Ital Dermatol Venereol 2010;145:57-78.

10. Gupta AK, Pandey SS, Pandey BL. Pharmacovigilance in 150 cases of plaque psoriasisand a case for conventional therapy. Asian journal of pharmaceutical and clinical research. Asian J Pharm Clin Res 2012;5:87-9.

How to cite this article: GuptaAK, Pandey SS, Pandey BL. Pharmacovigilance of conventional therapy in 250 cases of vitiligo at tertiary specialty care. Int J Med Public Health 2013;3:64-6.

Source of Support: Nil, Conflict of Interest: None declared. 